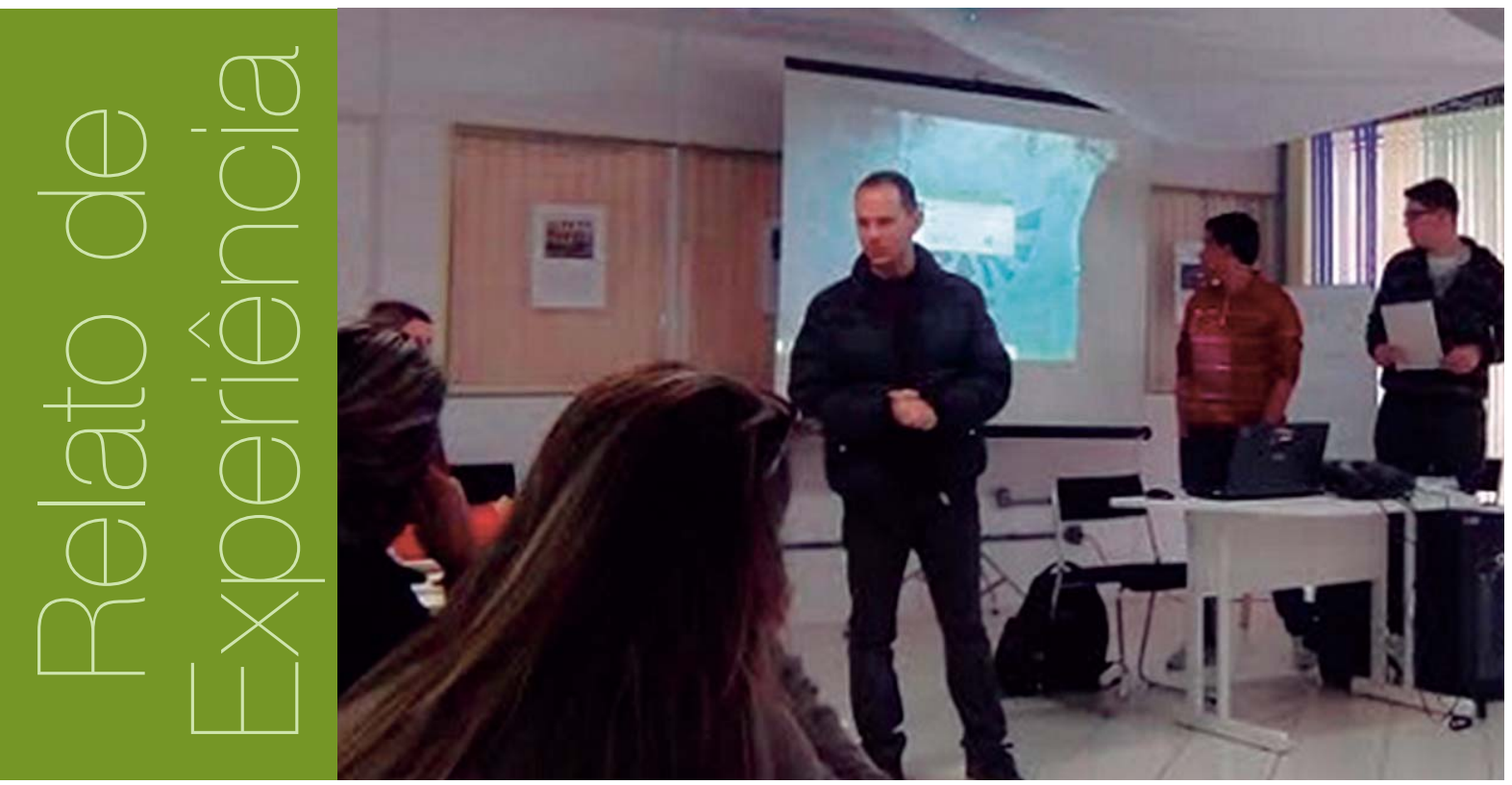

\title{
Bibliotecas em Transformação: Relato de Experiência
}

\author{
Alexandre Perin de Souza - alexandre.perin@ifsc.edu.br \\ Camila Koerich Burin² - camila.burin@ifsc.edu.br
}

\section{RESUMO}

Este artigo apresenta o relato de experiência do projeto de extensão denominado Bibliotecas das Escolas Municipais de Lages (SC) em Transformação. 0 objetivo do projeto foi 0 desenvolvimento de um software para controlar serviços presentes em uma biblioteca de escola pública municipal. 0 projeto de extensão foi executado em duas edições. A primeira edição teve como meta o planejamento do software. A segunda edição foi dedicada ao desenvolvimento do software. 0 principal resultado após a execução do projeto foi um software capaz de atender às necessidades das bibliotecas das escolas municipais de Lages (SC).

\section{PALAVRAS-CHAVE}

Biblioteca escolar. Software para biblioteca. Biblioteca e tecnologia.

\section{ABSTRACT}

This work presents the report extension project experience called Libraries of public schools in Lages (SC) in transformation. The goal of the project was the development of a software to control services present in a public school library. The extension project was executed in two editions. The first edition had as goal planning of the software. The second edition was dedicated to the software development. The main result after the execution of the project was a software capable of meeting the needs of libraries of public schools in Lages (SC).

\section{KEYWORDS}

School library. Software for library. Library and technology.

\footnotetext{
1 Doutor em Engenharia (UFSC, 2011) e docente de Informática do IFSC - Câmpus Lages (SC).

2 Mestre em Ciência da Informação (UFSC, 2009) e bibliotecária no IFSC - Câmpus Lages (SC)
} 


\section{Relato de experiência}

Uma característica marcante do século XXI (2015) é a utilização de tecnologia pelas organizações. 0 objetivo principal está em poder ofertar produtos e serviços com melhor qualidade. Nas bibliotecas, para melhorar a qualidade dos seus serviços, constata-se a utilização de tecnologias para possibilitar: maior rapidez na recuperação da informação, acesso a uma maior quantidade de dados, segurança na transferência de informações, racionalização de recursos financeiros e humanos (BARRETO; CARVALHO, 1997). Além disso, Côrte et al. (2002) reforçam que a utilização de tecnologias é uma necessidade vital para as bibliotecas, pois aquelas que quiserem oferecer melhores serviços devem utilizar sistemas informatizados que privilegiem as etapas do ciclo documental.

Nas bibliotecas de Lages (SC) a realidade se mostra da seguinte maneira: vários atendentes/ supervisores das bibliotecas são servidores sem formação na área e muitos possuem pouca experiência com uso do computador. Nas bibliotecas há computadores (muitos com recursos limitados) e 0 acesso à Internet é bastante precário (quando há). 0 cotidiano delas mostra que a maioria das atividades envolve procedimentos básicos: catalogação de obras, empréstimos, reservas, devoluções e geração de relatórios.

Para Cunha e Cavalcanti (2008), um software de biblioteca refere-se ao programa de computador que realiza a automação de atividades de uma biblioteca. Há diversos softwares para bibliotecas: Pergamum, SophiA, etc. Porém, considerando a realidade das bibliotecas de Lages (SC), a equipe executora, dentro do projeto "Bibliotecas das escolas municipais de Lages em transformação", resolveu desenvolver um novo software, em razão de: 1) As bibliotecas de Lages (SC) possuírem escassos recursos financeiros para adquirir e manter um software. 2) As funcionalidades dos softwares analisados atenderem em parte a realidade das bibliotecas. 3) 0 software deve ser executado em computadores com recursos de processador e memória limitados.

Com recursos do Edital APROEX 03/2014 do Instituto Federal de Santa Catarina (IFSC), entre março a junho de 2014, bibliotecários do IFSC - Câmpus Lages, um professor de computação e dois alunos bolsistas do curso Técnico em Informática, trabalharam na obtenção das necessidades dos bibliotecários das escolas de Lages (SC). Em uma 2ª edição do projeto, de setembro de 2014 a agosto de 2015, trabalhou-se na construção de um software (denominado de SimpleLibrary).

A metodologia utilizada no projeto está sintetizada em duas etapas: na primeira, o foco principal residiu no entendimento do funcionamento das bibliotecas de Lages (SC). Nesta etapa foram desenvolvidas duas atividades de destaque. A primeira delas compreendeu a aplicação de um questionário a um conjunto de 21 bibliotecas. A segunda atividade se resumiu na análise das respostas coletadas e na construção de um modelo que permitisse entender as informações gerenciadas pelas bibliotecas.

Na segunda etapa, uma reunião foi realizada Câmpus Lages do IFSC (Figura 1) para validar 0 trabalho produzido. Na reunião, a equipe executora apresentou um protótipo computacional. Foram dois os principais resultados obtidos a partir da reunião. 0 primeiro ratifica o entendimento da equipe executora acerca do funcionamento das bibliotecas, ou seja, a compreensão do funcionamento dos seus processos internos: catalogação de obras, empréstimos, etc. 0 segundo mostrou que, em razão do perfil das bibliotecárias (pouca experiência em informática), as interfaces gráficas precisariam de refinamentos para permitir uma melhor navegabilidade e uso do software.

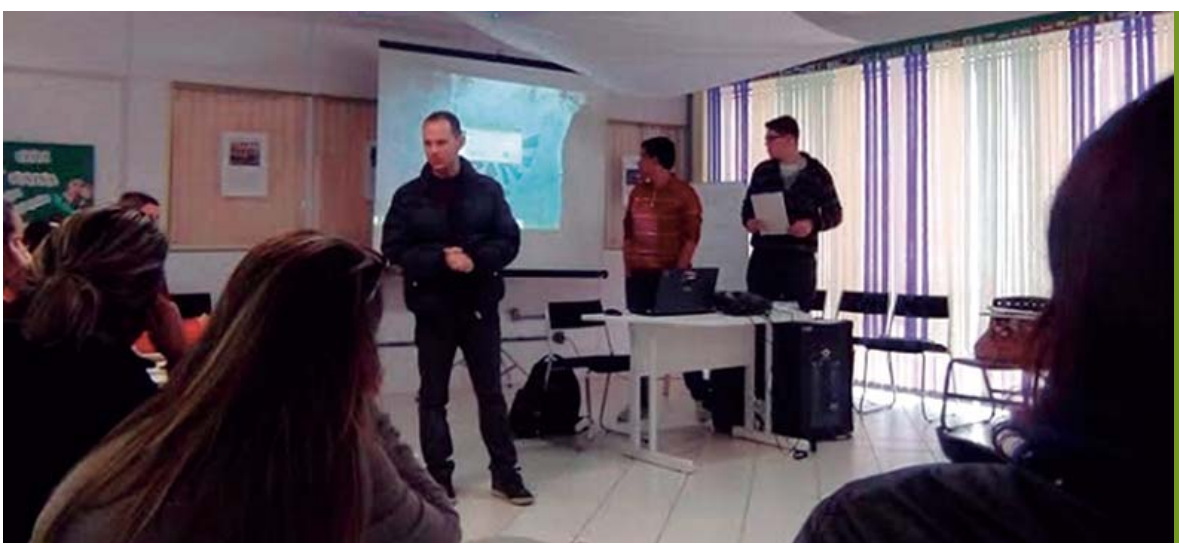

Figura 1: Registro da apresentação do protótipo computacional para bibliotecárias.

Fonte: Projeto de extensão. 
Concluída a atividade de validação, passou-se para a definição das tecnologias de informação utilizadas na construção do software. As principais tecnologias utilizadas foram: Java Development Kit, MySQL, iReport Designer e GitHub. Estas tecnologias foram escolhidas levando-se em conta dois aspectos: o primeiro foi a experiência da equipe executora com as tecnologias e o segundo está relacionado ao uso e à distribuição destas tecnologias que não implicam custos financeiros

Ainda na etapa dois, partiu-se para a construção do software. Nesta etapa, utilizou-se o processo de desenvolvimento incremental (PRESSMAN, 2011). Este processo tem como vantagem principal a entrega de versões em tempos pré-definidos para ajustes e melhorias, contando com a constante participação do usuário.

Os módulos voltados ao gerenciamento de informações de autores, usuários, bibliotecários e editoras foram finalizados. 0 módulo de gerenciamento de obras exigiu mais tempo e esforço de desenvolvimento, pois é complexo em detalhes. A Figura 2 apresenta um exemplo de interface gráfica que permite a inclusão de uma nova obra. É possivel informar autores, editoras, fornecedor e assuntos relacionados à obra (matemática, línguas, etc.) e inserir uma imagem da mesma.

Figura 2: Interface gráfica de cadastro de obra e exemplar.

Fonte: Elaborada pelos autores.

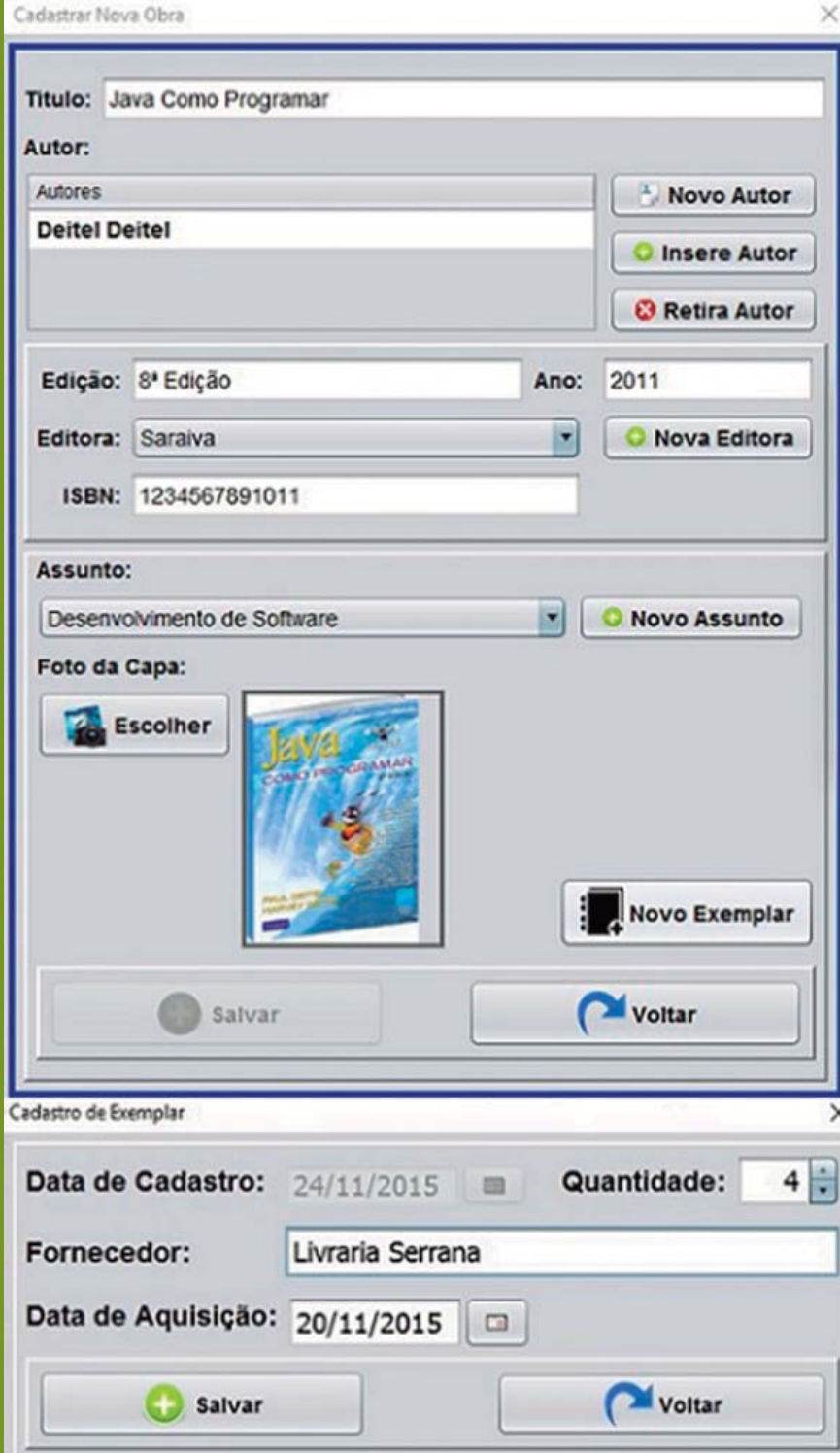

A funcionalidade relacionada ao empréstimo de obra foi implementada e serviu de base para 0 desenvolvimento da devolução e da reserva de obras. A Figura 3 ilustra a interface gráfica que permite realizar empréstimos de obras. 


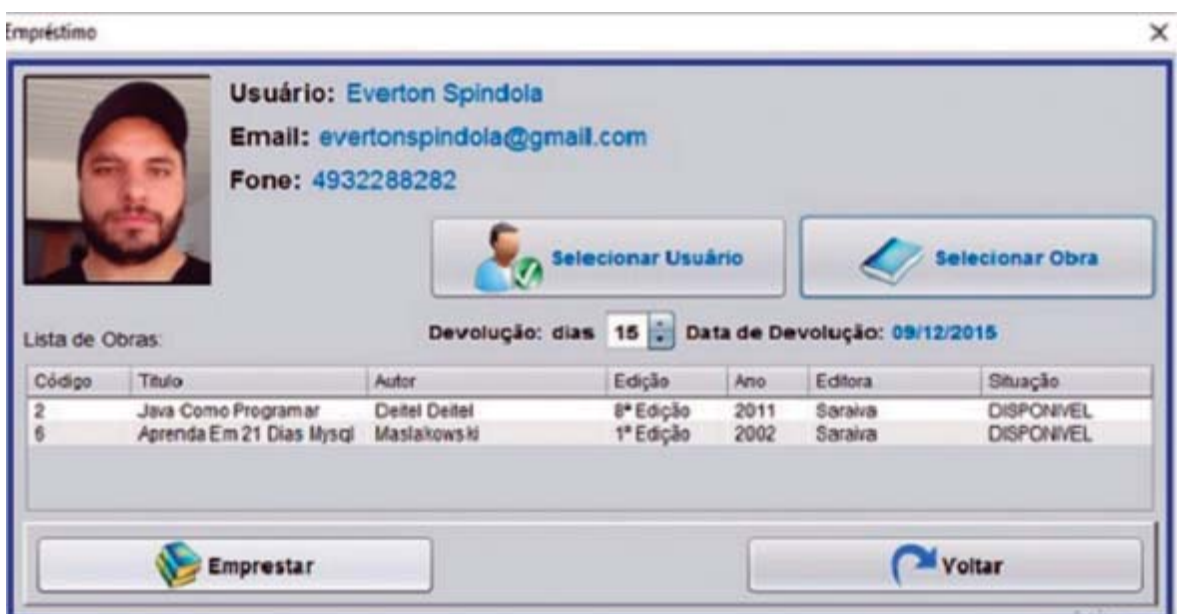

Para a reserva de obras, implementou-se uma política de prioridade de reserva, baseada na data da reserva mais antiga. Sem a necessidade de intervenção do assistente de biblioteca, 0 software determina qual usuário tem prioridade na reserva.

0 módulo voltado a devoluções de obras também foi desenvolvido e os relatórios básicos (autores, obras, exemplares, etc.) estão concluídos. Os relatórios complexos: acervo, devoluções e reservas são acompanhados de filtros (datas, por exemplo) que permitem gerar dados conforme a necessidade.

Pode-se resumir em quatro os principais resultados advindos deste projeto: o primeiro deles está relacionado à participação dos alunos bolsistas do projeto e 0 esforço dos mesmos para entender o funcionamento dos processos presentes nas bibliotecas. A partir do momento em que as informações a serem gerenciadas pelo software foram devidamente compreendidas pelos alunos bolsistas (desenvolvedores), a construção do software se tornou mais natural e precisa.

0 segundo aspecto reside no fato da presença constante das bibliotecárias do IFSC - Câmpus Lages (SC), que testaram, criticaram e/ou esclareceram questões relacionadas aos processos de negócios presentes nas bibliotecas. Isto permitiu poupar tempo e esforço para desenvolver 0 software e garantir que o produto pudesse atender às necessidades de uma biblioteca escolar de Lages (SC).

0 terceiro aspecto tem ligação com as bibliotecas visitadas e envolvidas neste projeto. A troca de experiência entre os supervisores das bibliotecas, a equipe executora e as bibliotecárias do IFSC - Câmpus Lages foi fundamental para melhorar a qualidade dos serviços prestados pelas bibliotecas. Muitas das bibliotecas visitadas neste projeto desconheciam formas e sistemas de catalogação de obras, além de realizarem controles pouco eficientes de empréstimos, usuários, devoluções, etc. Além disso, criou-se um fórum permanente de discussão onde os supervisores das bibliotecas de Lages (SC) podem inserir dúvidas, comentários e pedir ajuda em relação a alguma atividade inerente à biblioteca escolar.

No quarto aspecto, percebeu-se que a biblioteca do IFSC - Câmpus Lages se tornou referência para as demais bibliotecas. A partir deste projeto, capacitações e visitas são organizadas para que as bibliotecárias de Lages (SC) possam melhorar o seu trabalho e a sua formação.

\section{Referências}

BARRETO, Auta Rojas; CARVALHO, Elizabet Ramos de. Gestão de unidades de informação: manual. Curitiba: TECPAR; Brasilia: IBICT, 1997.

CÔRTE, Adelaide Ramos e et al. Avaliação de softwares para bibliotecas e arquivos: uma visão do cenário nacional. 2. ed. rev. e ampl. São Paulo: Polis, 2002.

CUNHA, Murilo Bastos da; CAVALCANTI, Cordélia Robalinho de Oliveira. Dicionário de biblioteconomia e arquivologia. Brasília: Briquet de Lemos, 2008.

PRESSMAN, Roger S. Engenharia de Software: uma abordagem profissional. 7. ed. Porto Alegre: AMGH, 2011.
Figura 3: Interface gráfica para empréstimo de obra.

Fonte: Elaborada pelos autores. 